\title{
Formulation of A Cookie Using
}

\section{Composite Flour Mixture}

By

Kaushalya NadeeshaniWijayasekara

This thesis is submitted in partial fulfillment of the degree of

Master of Science

InFood Science and Technology

Faculty of Graduate Studies

University of Sri Jayewardenepura

Nugegoda

Sri Lanka

2015 


\section{DECLARATION}

This work described in this thesis is carried out by me at University of Sri Jayewardenepura under the supervision of Dr. JagathWansapala, senior lecturer, Department of food Science and Technology, Faculty of Applied Sciences University of Sri Jayewardenepura, Sri Lanka.I described the results of my own independent study except where the references have been mentioned in the text. No part of this dissertation has been submitted previously in candidature for a in this or any other university

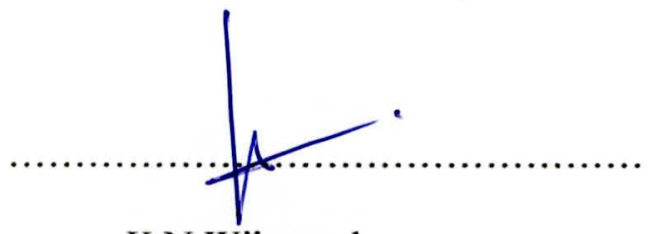

K.N Wijayasekara

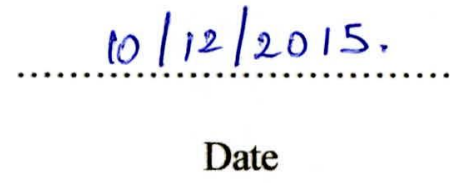

Date

I, Dr. Jagath Wansapala hereby certify that the statement in the preceding page made by the candidate is true and that this thesis is suitable for submission for the university for the purpose of evaluation.

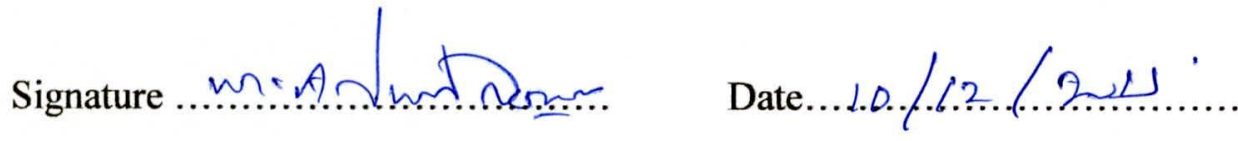
Supervisor

Dr. JagathWansapala

Department of food Science and Technology

Faculty of Applied Sciences

University of Sri Jayewardenepura

Sri Lanka 
Affectionately dedicated to my

Ever loving

Husband

NiranjanKannangara

And

Family 


\section{Table of Contents}

DECLARATION i

Table of Contents ....................................................................................................ii

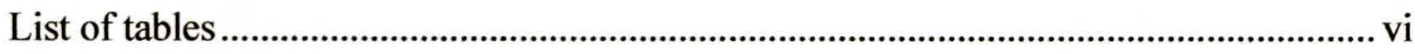

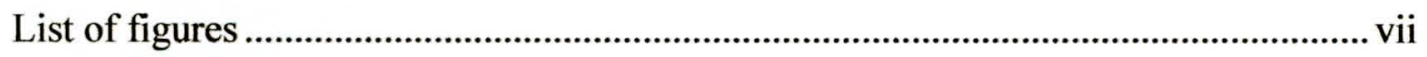

ACKNOWLEDGEMENT …...................................................................................viii

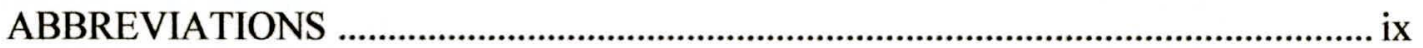

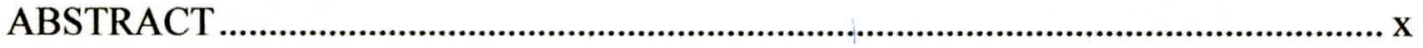

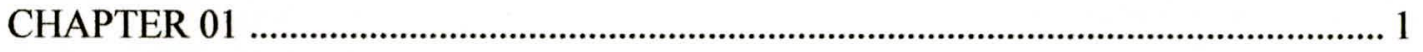

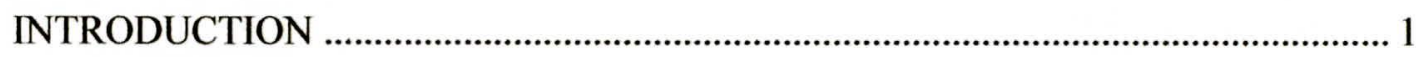

$1.1 \quad$ Background and Justification ......................................................................... 1

1.2 Major Objective (..................................................................................... 4

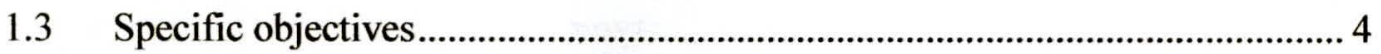

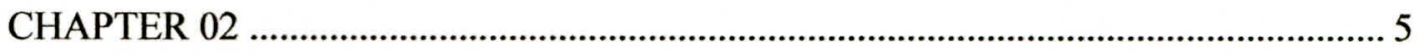

LITERATURE REVIEW ................................................................................ 5

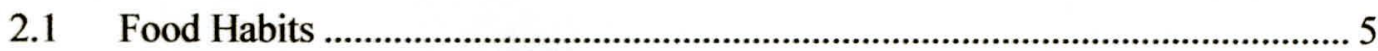

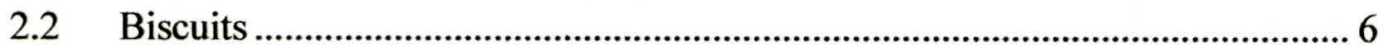

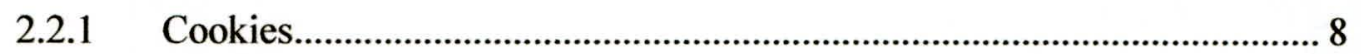

2.2.1.1 Classification of cookies ............................................................. 9

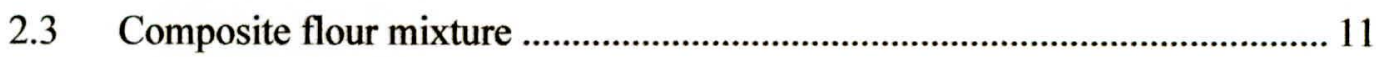

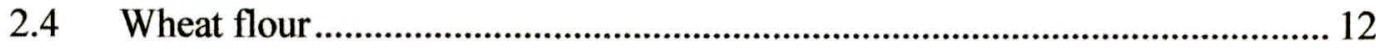




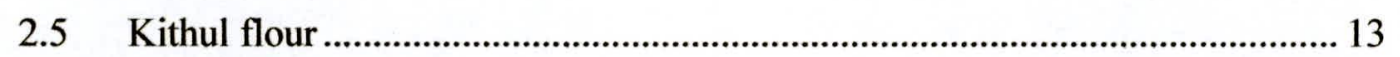

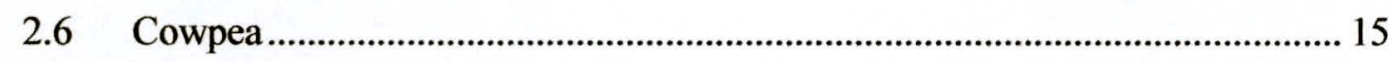

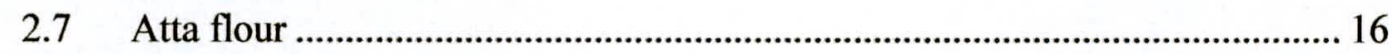

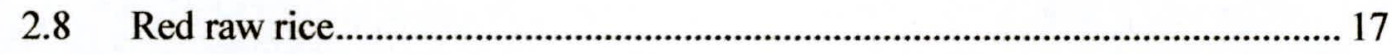

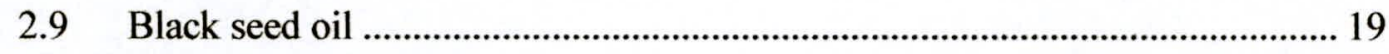

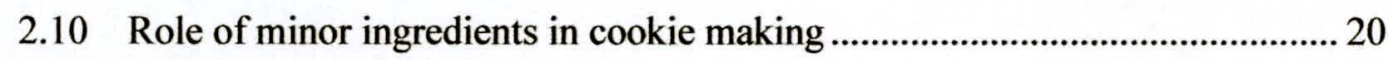

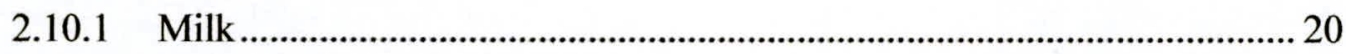

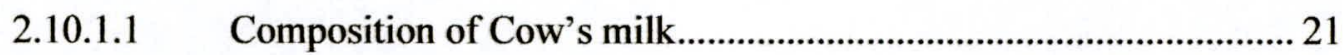

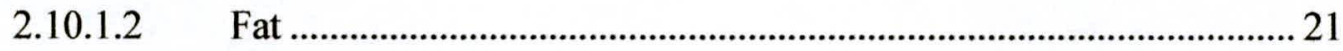

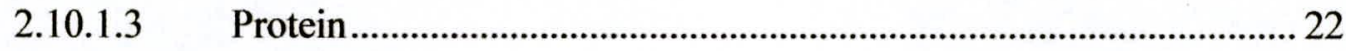

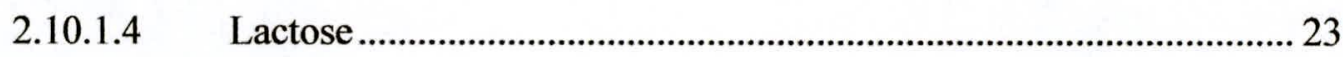

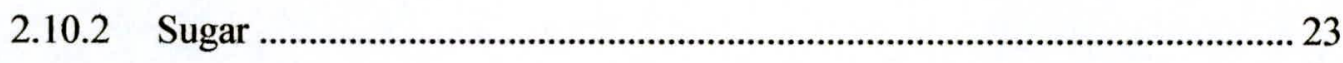

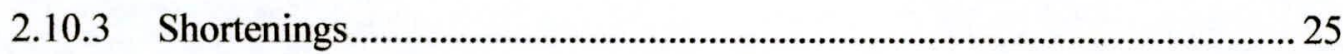

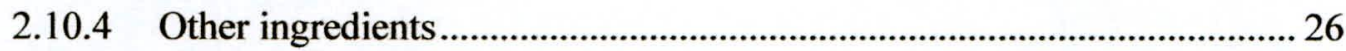

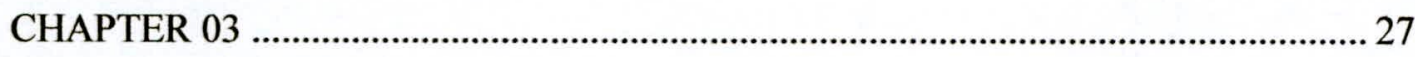

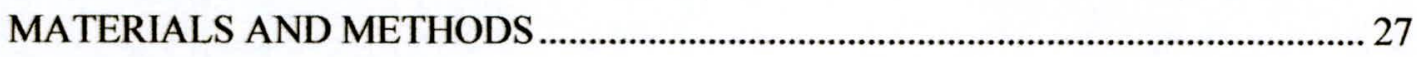

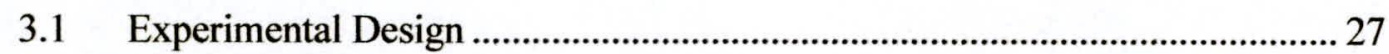

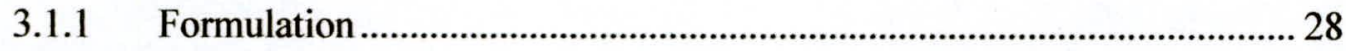

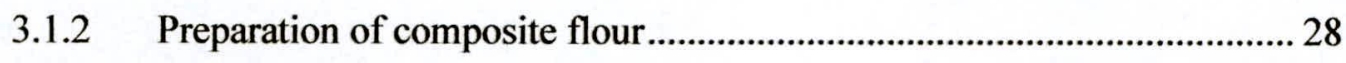

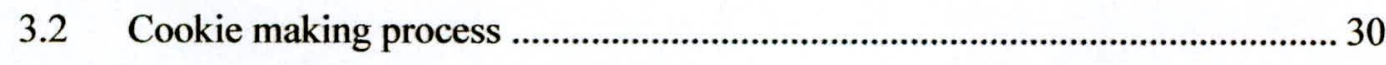

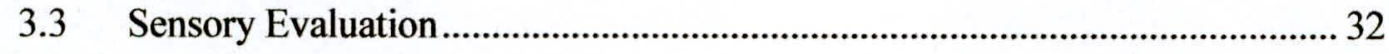




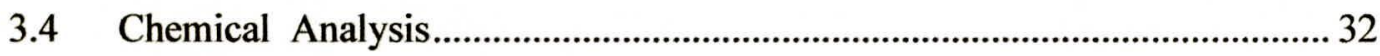

3.4.1 Moisture content as a percentage by mass .......................................... 32

3.4.2 Protein content as a percentage by mass .................................................. 33

3.4.3 Total fat content on wet basis as a percentage by mass ............................ 35

3.4.4 Carbohydrate content as a percentage by mass........................................ 37

3.4.5 Fiber content on wet basis as a percentage by mass ............................... 38

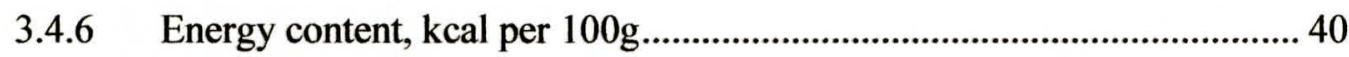

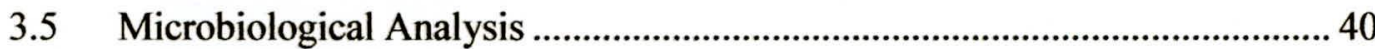

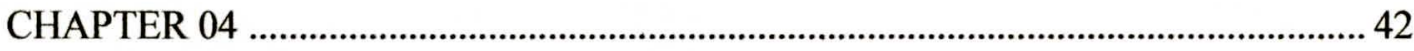

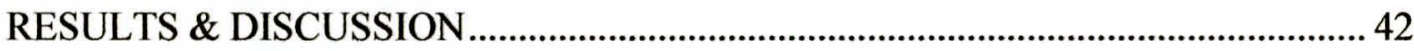

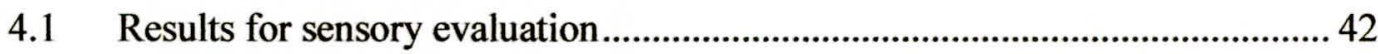

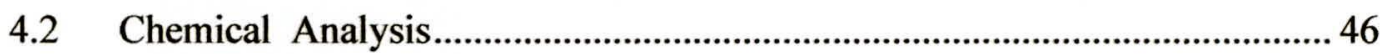

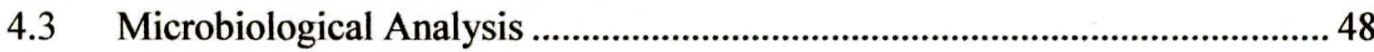

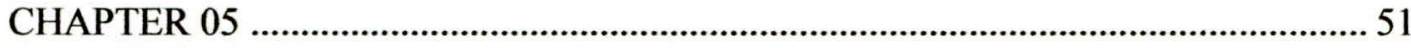

CONCLUSION

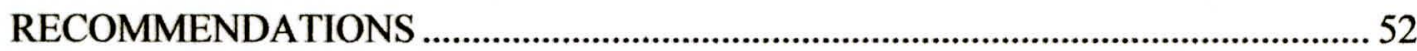

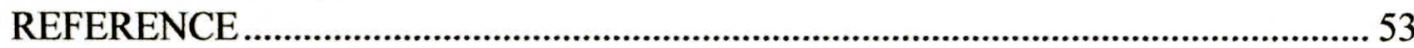

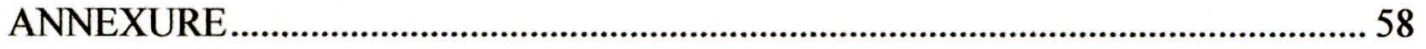




\section{List of tables}

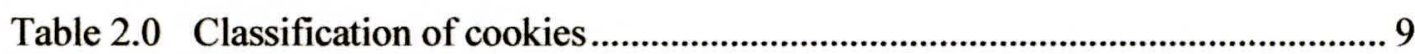

Table 2.1 Physio-Chemical Characteristics of Caryota palm pith flour (kithul flour) 14

Table 2.2 Nutritive value of Caryota palm, Kithul flour 15

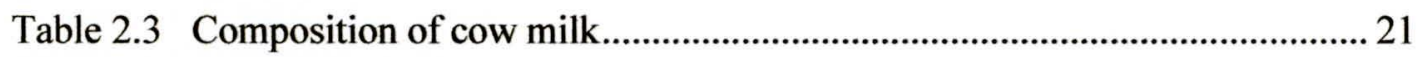

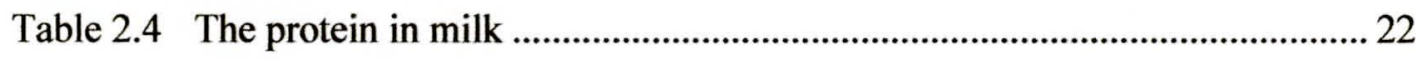

Table 3.1 Amount of Kitul and Cowpea flour added................................................29

Table 3.1 Composition of ingredients added for cookie making...............................29

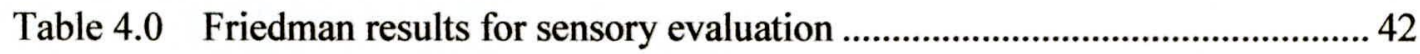

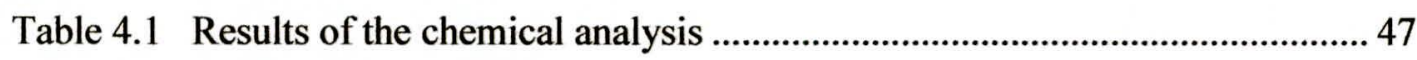

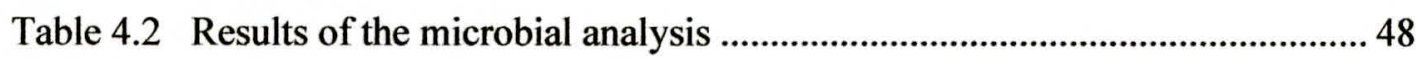

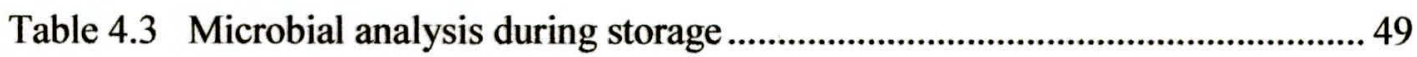




\section{List of figures}

Figure 2.1: Nutrition summary per 100g of wheat flour .......................................... 13

Figure $2.2 \quad$ Nutrition summaryper $100 \mathrm{~g}$ of Atta flour ............................................. 17

Figure 2.3 Nutrition summaryper $100 \mathrm{~g}$ of Red raw rice ....................................... 19

Figure 3.1: Production flow diagram of composite cookie ......................................... 30

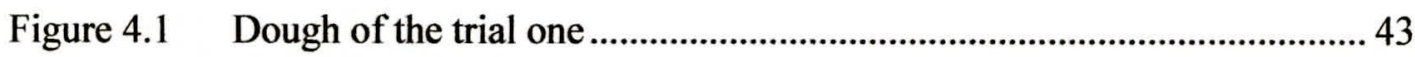

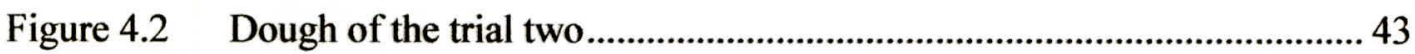

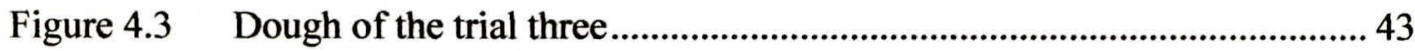

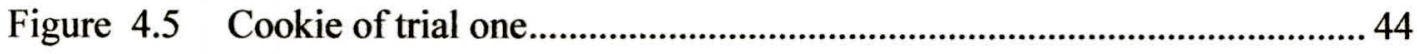

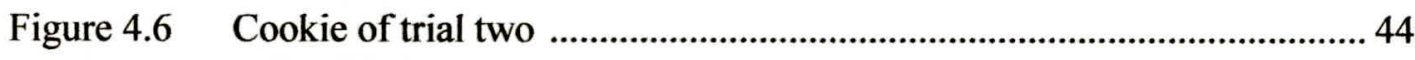

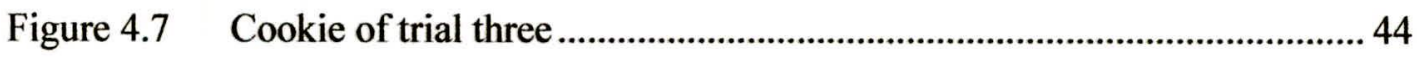

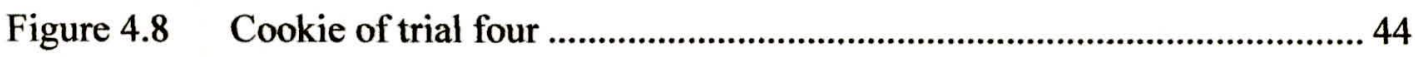




\section{ACKNOWLEDGEMENT}

First and foremost I wish to express my appreciation to my supervisor Dr. Jagath Wansapala, Dr. Jagath Wansapala, senior lecturer, University of Sri Jayewardenepura for his kind encouragements, valuable advice and guidance given me throughout the research.

My deep gratitude and greatest thanks are expressed to all the academic staff of the department of Food Science and Technology for giving their advices, help and encouragements in numerous occasions. I also thank the nonacademic staff of the Department for their support given on completion of my research.

Thanks are due to my husband Mr.NiranjanKannangara and my mother, father and the family who were always with me and gave their support and encouragements throughout my research. 


\section{ABBREVIATIONS}

TPC

SLS

RDA

WHO

GI

NCD

FAO
Total Plate Count

Sri Lanka Standards

Recommended Dietary Allowance

World Health Organization

Glycemic Index

Non communicable diseases

Food and Health Organization 


\section{ABSTRACT \\ Formulation of a cookie using composite flour mixture}

The modern consumers are demanding foods that show two main properties: the first one deals with the convenience whereas, as a second feature, traditional nutritional aspects of the food are expected from its regular ingestion. This study seeks to investigate the potentials of flours of cowpea, raw red rice, kithul, Atta and wheat flour blends along with black seed oil in cookie making which could be used as a meal replacement. Initially four trials were carried out to find out the best combination of composite flour mixture. by considering the nutritional values, cowpea and kitul flour amounts were considered as variables while rest of the flour amounts were kept constant in order to maintain the standard texture and nature of cookies. After carrying out the sensory evaluation on four treatments, most preferred treatment was selected to carry out the proximate and microbiological analysis where, $25 \mathrm{gKitul}$ flour, $5 \mathrm{~g}$ Cowpea flour, $50 \mathrm{gRed}$ rice flour, 15g Wheat flour, $25 \mathrm{gAtta}$ flour, 50g Sugar, 1 Egg and $2.5 \mathrm{ml}$ Black seed oil were used as highly nutritious cereals and pulses. The chemical analysis revealed that the selected composition has $1.2 \%$ of Moisture Content, $6.8 \%$ of Protein, $5.4 \%$ of total Fat, $80.4 \%$ of Carbohydrate, $3.2 \%$ of Fiber and an energy content of 398 $\mathrm{kcal} / \mathrm{g}$. Yeast and mold count of the tested sample were too low than spoilage level (1.0 $\left.\mathrm{x} 10^{1} \mathrm{~g}^{-1}\right)$. The formula developed could be used as a new variety of nutritionally rich cookie to the local market in Sri Lanka. Most importantly, this composite cookie contains proteins of high biologically value with balanced amount of essential amino acids achieved by including both cereals and legumes. The cookie is rich with micronutrients which are essential to maintain good health. The product also showed a shelf life of 12 weeks. 


\section{CHAPTER 01}

\section{INTRODUCTION}

\subsection{Background and Justification}

The development of new products is a strategic area of the food industry since the living style of people is shifting with the changes in a countries' economy. The modern consumers are demanding foods that show two main properties: the first one deals with the convenience whereas, as a second feature, traditional nutritional aspects of the food are expected from its regular ingestion. In a rapidly changing world, with altered food habits and stressful life styles, it is more and more recognized that a healthy digestive system is essential for the overall quality of life (Brouns et al., 2002). This situation could be observed especially among the people resided in urban areas. The food habit of people is one factor that has changed with the said life style. This has created an imbalance in the body with the excess of acidity linked to many diseases such as cancer, osteoporosis, heart disease, arthritis, skin problems amongst others. Alteration of food habits such as changes in the time of consumption, missing meals are now very common, particularly due to the busy and stressful life style. In the midst of these facts, fast foods have now become very popular. Convenience, availability at any time, affordability are the driving forces towards this trend. So, fast food appears to be the solution, except that it is not nutritionally balanced and, therefore, unhealthy in the long run if consumed on a regular basis.

At present Sri Lankan fast paced society also forces people to lead hectic lives, people of all strata of society are turning to junk food, fast food, instant food, picked up at 
cafes, restaurants, and wayside eateries on their way to school or office. This has resulted a dreadful impact on the collective digestive systems resulting in a host of preventable diseases such as diabetes, hypertension and cardiac problems that are both long lasting and life threatening. Obesity is the starting point. But to reach that point it takes years of over eating, especially at a young age.

Considering this point, the World Health Organization (WHO) stated that there is now a global obesity epidemic with some $70 \%$ of persons ( men, women and children) getting rounder at the waist every day, every year and ending up with various NCDs. Sri Lanka's Health Ministry, endorses this when it says NCDs are the leading cause of death, which is why it has launched a ' Healthy Lifestyle \& Nutrition' programme island wide, targeting people of all ages from the very young to the very old. Furthermore, among children it is possible to observe that many are overweight. Obesity is a developing pattern now in Sri Lankan children. This is mainly because they are busy with their education, which emphasizes that they are not spending energy: only taking in energy. So their bodies gain weight.

One of the best solutions for this tendency is a meal replacement, such a food should be able to fulfill all nutritional requirement of a particular meal, take a lesser time to consume and ready to eat. This will be helpful to address many food based problems in a busy life style. Among the different types of readily available meal replacements, cookies hold an important position in food industry due to its wider consumption base, relatively long shelf life, more convenience and good eating quality. Long shelf life of cookies makes large scale production and distribution possible. Cookies are made in a variety of style using an array of ingredients including sugars, spices, chocolates, butter, 
peanut butter, nuts or dried fruits. (Waheed, 2010). These are ideal for nutrient availability, palatability, compactness and convenience. They differ from other bakery products like bread and cakes because of having low moisture content, comparatively free from microbial spoilage long shelf life of the product.

Cookies are widely consumed all over the world by both adults and children alike. By now they represent the largest category of snack foods in most parts of the world. Among many of baked products especially cookies are produced from wheat flour. However, consumption of wheat flour is not healthy as it seems. One remedy for this is to incorporate several types of flour, so that it would become healthier and nutritious. Efforts have been made to promote the use of composite flour, in which flours from locally grown crops and high protein, seeds totally or partially replace wheat flour for use, in cookies thereby decreasing sole dependency on wheat and enhancing production of protein enriched products (Olaoye et al., 2006). Usually, the aim of producing composite flour is to get a product that is better than the individual components. Better mean improved properties or performances, or in some cases, improved economies. In selecting the components, to be used in composite flour blends, the materials, should preferably be readily available, culturally, acceptable and provide increased nutritional potential, (Akobundu et al., 1998).

During the past decade, the lifestyle of Sri Lankans changed dramatically. People struggle so much in surviving in the competitive society. Among the changed habits, food consumption is in the top of the list. The busy life schedules of both adults and children, has limited or rather taken away the available time to have a nutritious meal leisurely. However the number of studies carrying out on composite flour mix as a meal 
replacement, especially cookies are limited. Moreover the main lack of products is that their over consumption violates balanced diets for nutrients and energy value. Considering these, this research seeks to investigate the potentials of flours of cowpea, raw red rice, kithul, atta and wheat flour blends in cookie making which could be used as a meal replacement. This product would provide balanced nutrients with the convenience of eating.

\subsection{Major Objective}

Formulation of a cookie using composite flour mixture

\subsection{Specific objectives}

To identify the optimal composition of ingredients

To analyze the product

To carry out sensory evaluation 